\title{
Mode of arrival to the emergency department - a national, cross-sectional study in Sweden
}

Joakim HENRICSON ( $\square$ joakim.henricson@regionostergotland.se )

Linköping University

Ulf EKELUND

Skåne University Hospital, Lund University

Jens HARTMAN

Region Östergötland

Bruno ZIEGLER

Akutkliniken, Universitetssjukhuset Örebro, Örebro Universitet

Lisa KURLAND

Akutkliniken, Universitetssjukhuset Örebro, Örebro Universitet

Daniel BJÖRK WILHELMS

Linköping University

\section{Research Article}

Keywords: Sweden, triage, emergency service, hospital, demography, after hours care, delivery of health care

Posted Date: June 21st, 2021

DOl: https://doi.org/10.21203/rs.3.rs-620581/v1

License: (c) (1) This work is licensed under a Creative Commons Attribution 4.0 International License.

Read Full License 


\section{Abstract}

Background: Swedish Emergency Departments (EDs) see 2.6 million visits annually. Sweden has a strong tradition of health care databases, but mode of arrival to the ED is not documented in any registry. The situation is similar in most of Europe.

The aim of the study was to provide a national overview of the mode of arrival, medical acuity according to triage, chief complaints, and hospital admission rates for adult patients ( $\geq 18$ years) visiting Swedish EDs during 24h.

Methods: A national cross-sectional study including all patients at 43 of Sweden's 72 EDs during 24 hours on April 25 $5^{\text {th }}, 2018$.

Mode of arrival, medical acuity at triage, admission and basic demographics were registered by dedicated assessors present at every ED for the duration of the study. Descriptive data are reported.

Results: A total of 3875 adult patients (median age 59; range 18 to $107 ; 50 \%$ men) were included in the study. Complete data for mode of arrival was reported for 3693 patients $(98 \%)$. The most common mode of arrival was self-referred walk-in $(n=1310 ; 34 \%)$, followed by ambulance $(n=920 ; 24 \%)$, referral from a general practitioner $(n=497 ; 13 \%)$, and telephone triage referral by the national healthcare guide service "Healthcare Guide 1177" ( $n=409 ; 10 \%)$. In patients 18 to 64 years, self-referred walk-in was most common, whereas transport by ambulance dominated in patients $>64$ years.

Of the 3365 patients that received an acuity level at triage, 4\% were classified as Red (Immediate), $18 \%$ as Orange (very urgent), $47 \%$ as Yellow (Urgent), $26 \%$ as Green (Standard), and $5 \%$ as Blue (Non-Urgent).

Patients presented with very diverse complaints but about a quarter had abdominal or chest pain.

Overall, the admission rate was $27 \%$. Arrival by ambulance was associated with the highest rate of admission (486 of 920; 53\%), self-referred walk-in and telephone triage referrals were less often admitted.

Conclusion: Self-referred walk-in was the overall most common mode of arrival followed by ambulance. Patients arriving by ambulance were often elderly, critically ill and were often admitted to in-patient care, whereas arrival by self-referred walk-in was more common in younger patients.

\section{Background}

All 10 million citizens in Sweden have unrestricted access to tax subsidized, public acute and emergency care, which is provided either by general practitioners (GPs) at outpatient clinics, or at emergency departments (EDs). Swedish EDs have approximately 2.6 million visits annually and the number is increasing steadily (1). 
The quality of emergency care is an area of increasing interest both in Sweden and elsewhere. Sweden has a tradition of comprehensive healthcare quality registries but the National Quality Registry for EDs (2) has little governmental support and the coverage is as of yet approximately $40 \%$. Hence, national data on ED health care delivery, such as mode of arrival, is lacking.

There are only a few single-centre studies on the mode of ED arrival in Sweden. The most recent study indicated that ambulance was the most common mode of arrival followed by referrals or recommendations from various telephone-based healthcare services, such as the national service "Healthcare Guide 1177" or primary care telephone services (3). Other single-centre studies confirm that many patients are referred to the ED from a previous encounter with healthcare $(3,4)$. As in other highincome countries, there is an ongoing debate in Sweden concerning the appropriate use of emergency care, specifically focusing on self-referred walk-in and low-acuity patients in EDs (5). To date, however, this debate is largely uninformed since the national panorama of ED arrivals and their associated medical acuity remains unknown.

Thus, the aim of this study was to provide a national overview of the mode of arrival, medical acuity according to triage, chief complaints and hospital admission rates for adult patients visiting Swedish EDs during $24 \mathrm{~h}$.

\section{Methods}

This was a national, cross sectional study including all adult (18 years or above) patients attending Swedish EDs during 24 hours on April 25th, 2018.

The study was approved by the regional ethics review board in Linköping (permit number 2018/50 - 31). Patients were informed about the study by posters in the waiting rooms in all participating EDs, and consent was presumed unless patients actively declined participation.

Participating sites were recruited in a two-step process: All Swedish EDs were initially contacted by an email to the head of the department, followed by a telephone call. Participation was confirmed in writing by the head of department. Each participating ED was instructed to appoint a local study coordinator who was responsible for the study at the site.

\section{Acuity Assessment}

Most EDs in Sweden use the RETTS system (6) to classify patients to one of five triage levels - blue, green, yellow, orange or red reflecting the planned acceptable waiting time to assessment by a doctor. Blue indicates a limited need of emergency care and red an immediately life-threatening condition. The reported RETTS classifications were used as indicators of medical acuity.

\section{Data collection}


Data collection was divided into an initial phase and a secondary phase. In the initial phase, each ED filled in a form (Appendix 1) to register mode of arrival and information on each adult arriving to the ED during the 24-hour study period. The patients were asked by the front desk personnel about prior contacts with any healthcare provider relating to the present chief complaint.

Data collection was supervised by the local coordinators based on instructions from the central study coordinator. Typically, the initial patient registration was performed either by dedicated personnel at the front desk or by the ED nurse receiving the ambulance for patients arriving by ambulance. Standardized training was provided in video-format and supplemented by written instructions.

Data acquisition concerning medical acuity according to RETTS, chief complaints, admission to inhospital care and data losses was performed in the secondary phase of data collection, after the initial 24-hour study period.

All data was compiled in a spreadsheet by the local coordinator at each ED and delivered to the central study coordinator.

\section{Definitions}

In the present study, mode of arriva/ was broadly defined as the most recent, previous healthcare encounter or physical pathway leading up to the ED visit. Self-referred patients without prior healthcare contacts before presentation to the ED were registered as walk-in arrivals. Other patients were assigned one of the following categories: (referral from) Healthcare Guide 1177; general practitioner with referral; general practitioner without referral; other in-hospital doctor with referral; other in-hospital doctor without referral; internet medical service with referral; internet medical service without referral; referred by other healthcare provider, return visit (scheduled); arrival by ambulance. Only one alternative was allowed for each patient. Patients arriving by ambulance were not asked about previous contacts, since only the most proximal events leading to the ED visit was considered in this study.

\section{Data analysis}

The number of patients with the different modes of ED arrival was counted and divided by the total number of patients to gain the percentage distribution. A similar procedure was used to calculate percentage distribution of different modes of arrival for each ED that participated in the study.

The total number of patients per reported medical acuity level was calculated and divided by the total number of patients, as well as for each ED respectively, and presented as a percentage distribution. For the assessment of medical acuity patients classified as Orange and Red according to RETTS were considered as one group named Critical illness.

The percentage distribution for the in-hospital admission rate for respective mode of arrival was calculated by adding up all admitted patients per mode of arrival and dividing that by the total number for each mode of arrival, respectively. 


\section{Results}

Of the invited 72 EDs, 55 agreed to participate, 11 declined and six never responded. Two EDs left the study before submitting data (Fig. 1). Forty-three of the remaining EDs (60\%) submitted data for analysis, see Appendix 2. In total, 3875 adult patients were included, median 59 years of age; range 18 to 107 years; $50 \%$ men. The number of complete data for the different variables is presented in Table 1.

Table 1

Number of complete and missing data .

\begin{tabular}{|llllllll|}
\hline & $\begin{array}{l}\text { Mode } \\
\text { of } \\
\text { Arrival }\end{array}$ & Sex & Age & $\begin{array}{l}\text { Triage Category } \\
\text { According to } \\
\text { RETTS* }\end{array}$ & $\begin{array}{l}\text { Initial } \\
\text { Diagnosis }\end{array}$ & $\begin{array}{l}\text { Diagnosis } \\
\text { According to } \\
\text { RETTS }\end{array}$ & Admission \\
\hline $\begin{array}{l}\text { Complete } \\
\text { Data }\end{array}$ & 3693 & 3782 & 3785 & 3277 & 3776 & 3640 & 3718 \\
$\begin{array}{l}\text { Missing } \\
\text { Data }\end{array}$ & 92 & 3 & 0 & 508 & 9 & 145 & 67 \\
\hline
\end{tabular}

Figure 2 shows that the most common mode of arrival was self-referred walk-in (34\%), followed by arrival by ambulance (24\%), referral from a general practitioner (13\%), and referral from Healthcare Guide 1177 (10\%).

Self-referred Walk-in was also the most common mode of arrival for patients aged 18 to 29 years (271 of $596 ; 45 \%)$ and 30 to 64 years ( 614 of $1638 ; 37 \%$ ). Arrival by ambulance was the most common mode of arrival for patients between 65 and 80 years (341 of 1081; 32\%) and for those 81 years and older (294 of $569 ; 52 \%)$ (Fig. 3).

Of the 3875 included patients, were 3365 (87\%) triaged according to RETTS (remaining patients were either incorrectly triaged using acuity levels not included in the RETTS system or lacked acuity level). Of these, $4 \%$ were triaged as Red, $18 \%$ as Orange, $47 \%$ as Yellow, $26 \%$ as Green and $5 \%$ as Blue.

Three hundred eighty six of the 920 patients arriving by ambulance (42\%) were triaged as critically ill (RETTS Red or Orange), and 180 of the 1310 self-referred walk-in patients (14\%) (Table 2). 
Table 2

Acuity measured as triage priority according to Rapid Emergency Triage and Treatment System (RETTS)

by modes of arrival, as reported by the 43 EDs. Bold numbers indicate actual numbers of registered

patients for the respective acuity levels and modes of arrival. Horizontal percentages represent

distribution of acuity level per mode of arrival. Vertical percentages represent the distribution of mode of arrival per acuity level. GP = general practitioner. Other $\mathrm{Dr}=$ another in-hospital doctor.

\begin{tabular}{|c|c|c|c|c|c|c|c|}
\hline & Priority/A & Jity Accor & ing to RET & & & & \\
\hline Mode of Arrival & Red & Orange & Yellow & Green & Blue & Missing & Total \\
\hline Ambulance & $\begin{array}{l}10311 \% \\
71 \%\end{array}$ & $\begin{array}{l}283 \\
31 \%\end{array}$ & $\begin{array}{l}34938 \% \\
22 \%\end{array}$ & $\begin{array}{l}12614 \% \\
14 \%\end{array}$ & & $\begin{array}{l}\mathbf{5 6} 6 \% \\
11 \%\end{array}$ & $\begin{array}{l}920 \\
100 \%\end{array}$ \\
\hline & & $46 \%$ & & & Z\% & & \\
\hline Walk-in & $\begin{array}{l}212 \% \\
14 \%\end{array}$ & $\begin{array}{l}159 \\
12 \%\end{array}$ & $\begin{array}{l}50939 \% \\
32 \%\end{array}$ & $\begin{array}{l}32825 \% \\
37 \%\end{array}$ & $\begin{array}{l}836 \% \\
20 \%\end{array}$ & $\begin{array}{l}21016 \% \\
42 \%\end{array}$ & $\begin{array}{l}1310 \\
100 \%\end{array}$ \\
\hline & & $26 \%$ & & & & & \\
\hline GP with referral & & $\begin{array}{l}58 \\
12 \%\end{array}$ & $\begin{array}{l}25451 \% \\
16 \%\end{array}$ & $\begin{array}{l}12024 \% \\
14 \%\end{array}$ & & & $\begin{array}{l}497 \\
100 \%\end{array}$ \\
\hline & $6 \%$ & $10 \%$ & & & $4 \%$ & $8 \%$ & \\
\hline $\begin{array}{l}\text { Healthcare } \\
\text { Guide } 1177\end{array}$ & $61 \%$ & $\begin{array}{l}43 \\
11 \%\end{array}$ & $\begin{array}{l}18144 \% \\
11 \%\end{array}$ & $11428 \%$ & $154 \%$ & $5012 \%$ & $\begin{array}{l}409 \\
100 \%\end{array}$ \\
\hline & $4 \%$ & & & & $4 \%$ & & \\
\hline GP without & $42 \%$ & $229 \%$ & $11748 \%$ & $8133 \%$ & $73 \%$ & $156 \%$ & 246 \\
\hline & $3 \%$ & $4 \%$ & & & $2 \%$ & $3 \%$ & \\
\hline Other Dr without & $21 \%$ & 24 & $5840 \%$ & $4028 \%$ & $53 \%$ & $1611 \%$ & $\begin{array}{l}145 \\
100 \%\end{array}$ \\
\hline & $1 \%$ & & & & $1 \%$ & & \\
\hline Other Dr with & $12 \%$ & $914 \%$ & $2844 \%$ & $1219 \%$ & $58 \%$ & $83 \%$ & 63 \\
\hline & $1 \%$ & $1 \%$ & $2 \%$ & & $1 \%$ & $2 \%$ & \\
\hline Referred by & $00 \%$ & $812 \%$ & $2842 \%$ & $2334 \%$ & $69 \%$ & $23 \%$ & $\begin{array}{l}67 \\
100 \%\end{array}$ \\
\hline $\begin{array}{l}\text { healthcare } \\
\text { provider }\end{array}$ & $0 \%$ & $1 \%$ & & & $1 \%$ & $0 \%$ & \\
\hline Return visit & $00 \%$ & $43 \%$ & $4840 \%$ & $3831 \%$ & 18 & $1311 \%$ & 121 \\
\hline & $0 \%$ & $1 \%$ & $3 \%$ & & $4 \%$ & & \\
\hline Internet medical & $00 \%$ & $00 \%$ & $2100 \%$ & $00 \%$ & $00 \%$ & $00 \%$ & $2100 \%$ \\
\hline with referral & $0 \%$ & $0 \%$ & & $0 \%$ & $0 \%$ & $0 \%$ & \\
\hline
\end{tabular}




\begin{tabular}{|c|c|c|c|c|c|c|c|}
\hline \multirow{3}{*}{$\begin{array}{l}\text { Internet medical } \\
\text { service, } \\
\text { without referral }\end{array}$} & \multicolumn{7}{|c|}{ Priority/Acuity According to RETTS } \\
\hline & $00 \%$ & $00 \%$ & $222 \%$ & $556 \%$ & $111 \%$ & $111 \%$ & $9100 \%$ \\
\hline & $0 \%$ & $0 \%$ & $0 \%$ & $1 \%$ & $0 \%$ & $0 \%$ & \\
\hline \multirow[t]{2}{*}{ Missing } & & & & & & $86100 \%$ & 86 \\
\hline & & & & & & $17 \%$ & \\
\hline \multirow[t]{2}{*}{ Total } & 145 & 610 & 1576 & 887 & 161 & 496 & 3875 \\
\hline & $100 \%$ & $100 \%$ & $100 \%$ & $100 \%$ & $100 \%$ & $100 \%$ & $100 \%$ \\
\hline
\end{tabular}

Table 3 shows that the most common chief complaint at ED presentation was abdominal pain (524; $14 \%)$, followed by chest pain $(369 ; 10 \%)$ and breathing problems $(278 ; 7 \%)$. 
Table 3

The 20 most common chief complaints as reported by the patients upon presentation to a ED, categorized in accordance with the triage system (RETTS). The Average column shows the total number and proportion of patients with a specific chief complaint in relation to the total number of patients in the study (3875). The Percent colums, in the Range segment, indicate the higest and lowest percentage of patients with a chief complaint as reported per emergency department (ED) in relation to the total number of patients at each ED.

\begin{tabular}{|c|c|c|c|c|}
\hline & \multicolumn{2}{|c|}{ Average } & \multicolumn{2}{|l|}{ Range } \\
\hline & & & Highest & Lowest \\
\hline Chief Complaints & $\mathbf{N}$ & Percent & Percent & Percent \\
\hline Abdominal pain/Flank pain & 524 & $14 \%$ & $26 \%$ & $0 \%$ \\
\hline Chestpain/Rib cage pain & 369 & $10 \%$ & $23 \%$ & $4 \%$ \\
\hline Respiratory disorder/Dyspnea/Respiratory distress & 278 & $7 \%$ & $15 \%$ & $0 \%$ \\
\hline Injury hand/Arm & 212 & $5 \%$ & $22 \%$ & $0 \%$ \\
\hline Extremity pain & 144 & $4 \%$ & $11 \%$ & $0 \%$ \\
\hline Injury/Trauma/Head & 129 & $3 \%$ & $9 \%$ & $0 \%$ \\
\hline Vertigo & 115 & $3 \%$ & $12 \%$ & $0 \%$ \\
\hline Non-specifik illness & 110 & $3 \%$ & $18 \%$ & $0 \%$ \\
\hline Injury Foot & 106 & $3 \%$ & $9 \%$ & $0 \%$ \\
\hline Neurological loss/TIA & 97 & $3 \%$ & $18 \%$ & $0 \%$ \\
\hline Non-specifik infection & 96 & $2 \%$ & $10 \%$ & $0 \%$ \\
\hline Fever & 86 & $2 \%$ & $7 \%$ & $0 \%$ \\
\hline Headache & 84 & $2 \%$ & $7 \%$ & $0 \%$ \\
\hline Abnormal heart rate & 82 & $2 \%$ & $9 \%$ & $0 \%$ \\
\hline Back pain & 77 & $2 \%$ & $8 \%$ & $0 \%$ \\
\hline Injury knee/Lower leg & 73 & $2 \%$ & $10 \%$ & $0 \%$ \\
\hline Injury hip/Femur & 65 & $2 \%$ & $9 \%$ & $0 \%$ \\
\hline Urinary complications & 52 & $1 \%$ & $7 \%$ & $0 \%$ \\
\hline Non-specifik extremity complications & 48 & $1 \%$ & $18 \%$ & $0 \%$ \\
\hline Sickness/Fatigue & 48 & $1 \%$ & $27 \%$ & $0 \%$ \\
\hline Other/Missing & 1080 & $28 \%$ & & \\
\hline Total & 3875 & $100 \%$ & & \\
\hline
\end{tabular}


The overall hospital admission rate for the entire cohort was $27 \%$ (1056 patients). Arrival by ambulance was associated with the highest rate of hospital admission at 53\% (486 of 920 ), followed by self-referred walk-in at $17 \%$ (222 of 1310), see Table 4. The admission rate for those triaged as critically ill was $59 \%$ (446 of 755), and it was $26 \%$ (405 of 1574) for the Yellow, $13 \%$ (112 of 884 ) for the Green, and $2 \%$ (4 of 161) for the Blue patient groups, respectively.

Table 4

The number and percentage of patients admitted to in-hospital care per to mode of arrival. $\mathrm{GP}=$ general practitioner. Other $\mathrm{Dr}=$ another in-hospital doctor.

\begin{tabular}{|llll|}
\hline & Admission & Total & Percentage \\
\hline Ambulance & 486 & 920 & $53 \%$ \\
\hline Walk-in & 222 & 1310 & $17 \%$ \\
\hline GP with referral & 132 & 497 & $27 \%$ \\
\hline Healthcare Guide 1177 & 58 & 409 & $14 \%$ \\
\hline GP without referral & 44 & 246 & $18 \%$ \\
\hline Other Dr without referral & 40 & 145 & $28 \%$ \\
\hline Other Dr with referral & 22 & 63 & $35 \%$ \\
\hline Referred by other healthcare provider & 19 & 67 & $28 \%$ \\
\hline Return visit (Scheduled) & 14 & 121 & $12 \%$ \\
\hline Internet medical service, with referral & 1 & 21 & $5 \%$ \\
\hline Internet medical service, without referral & 0 & 9 & $0 \%$ \\
\hline Missing data & 18 & 86 & $21 \%$ \\
\hline
\end{tabular}

\section{Discussion}

This is the first nationwide study in Sweden describing mode of ED arrival, as well as the associated medical acuity, chief complaints, and hospital admissions rates for adult patients. The most common mode of arrival was self-referred walk-in which corresponded to approximately one third of all ED arrivals. A large proportion of the self-referred walk-ins were young and had less urgent medical needs, as indicated by low triage levels and admission rates. In contrast, patients arriving by ambulance were often elderly, critically ill, and were often admitted to in-hospital care.

The present results also show that a common mode of arrival is referral to the ED by the national healthcare guide service, Healthcare Guide 1177 (11\%). For these patients, critical illness or need for hospital admission were rare. Similar patterns have been reported in previous studies (7-10) which leads to the question whether some of these patients could be managed elsewhere in the healthcare system, 
and thereby decrease the strain on the EDs. This is an important issue, since crowding leads to an increased ED workload and longer waiting times, potentially affecting the quality of care especially for patients with time-sensitive conditions $(8,11)$.

Limited availability of primary care may partly explain why so many low acuity patients come to the ED, since primary care in Sweden mostly operates during office hours, and usually requires an appointment $(11-13)$. In addition, some patients may believe they will receive better care at the hospital ED or overestimate the urgency of their health issue $(9,10)$. Another factor is that emergency medicine is under development as a medical specialty in Sweden, and other specialities may sometimes still consider the ED as convenient venue for the management of semi-urgent outpatients. Hence there are several explanations to why the proportion of low acuity patients is large.

Further, the current study highlights large differences in modes of arrival between hospitals. This may partly be explained by geographical differences in the organization of acute care since, in some parts of the country, the ED may be the only healthcare available outside of office hours, and an ambulance may be the only available means of transportation for e.g., the elderly. However, geography cannot explain the large variation of low acuity patients arriving by self-referred walk-in, or those who have been in previous contact with primary care. Rather, our results indicate that there may be differences in the decisionmaking process leading up to ED referrals, and point to a need for clear criteria for ED care.

The findings of the current study underscore the need for continuous reporting of mode of arrival, as well as other basic information on ED patients on a national level. In contrast to Sweden and most other European countries, Australia has a well-developed system for continuously reporting mode of arrival for all ED patients (7) and we strongly suggest that such a model for national reporting be implemented in Europe as well. Such information would provide a better understanding of ED operations and allow us to optimize resource use and continuously monitor outcomes within emergency healthcare.

\section{Limitations}

There are some methodological limitations to this study. The initial triage classification and admission rate are rather blunt instruments for estimating medical acuity but are commonly used. Information about previous health care contacts was reported by patients and manually recorded with no means of quality control. Although two thirds of all EDs in Sweden participated, several EDs in the major cities (3 in Stockholm and 2 in Gothenburg) declined participation. However, the participating EDs are geographically evenly distributed in Sweden and include EDs of all sizes, and we therefore believe that the results are generalizable. It is a limitation that the study results are point estimates from one 24-hour period. However, the specific date was chosen to represent a day in the middle of the week and not during a holiday period to make it representative of regular ED operations.

\section{Conclusion}


Self-referred walk-in, arrival by ambulance and referral from primary care, either after a physical or telephone contact, were the predominating modes of arrival at Swedish EDs. Ambulance arrival was most common in patients $>64$ years of age, and self-referred walk-in in younger patients. Patients arriving by ambulance had the highest level of acuity and hospital admission rates. A nationwide, systematic registration of ED performance measures is necessary to enable continuous monitoring of ED health care delivery, including mode of arrival.

\section{Abbreviations}

$E D$

Emergency Department

GP

General practitioner

RETTS

Rapid Emergency Triage and Treatment System

\section{Declarations}

Ethics approval: The study was approved by the regional ethics review board in Linköping (permit number 2018/50-31). Patients were informed about the study by posters in the waiting rooms in all participating EDs, and consent was presumed unless patients actively declined participation.

Consent for publication: Not applicable

Availability of data and materials: The dataset used and analysed during the current study are available from the corresponding author on reasonable request.

Competing interests: The authors declare that they have no competing interests.

Funding: This work was supported by two grants from Region Östergötland to author DBW (LIO-532001 and LIO-700271).

Author UE is part of the AIR Lund (Artificially Intelligent use of Registers at Lund University) research environment and received funding from the Swedish Research Council (VR; grant no. 2019-00198).

The funding bodies had no role or influence over any aspect of this study. Open access funding was provided by Linköping University.

Author's contributions: DBW, LK, UE and BZ conceived the study. DBW obtained the necessary permits. DBW and UE obtained funding. DBW, JH and $\mathrm{JH}$ a coordinated data collection. $\mathrm{JH}, \mathrm{JHa}$ and DBW analyzed the data and drafted the manuscript. All authors discussed the results and commented on the manuscript. 
Acknowledgements: RN Erika Hörlin, Linköping, for valuable support in the data collection process.

\section{References}

1. Socialstyrelsen. Väntetider och patientflöden på akutmottagningar. www.socialstyrelsen.se; 2017 February 2017. Contract No.: 2017-2-6.

2. Svenska Akutvårdsregistret 2021 [Available from: https://www.ucr.uu.se/svar/.

3. Helmrot KZB. Telefonhänvisning till akuten bakom en stor del av besöken. Läkartidningen. 2016;113(20).

4. Goransson KE, De Waern M, Lindmarker P. Patients' pathway to emergency care: is the emergency department their first choice of care? Eur J Emerg Med. 2013;20(1):45-50.

5. Chmiel C, Huber CA, Rosemann T, Zoller M, Eichler K, Sidler P, et al. Walk-ins seeking treatment at an emergency department or general practitioner out-of-hours service: a cross-sectional comparison. BMC Health Serv Res. 2011;11:94.

6. Predicare AB - Rapid Emergency Triage and Treatment System [Available from: https://predicare.se/om-retts/.

7. Health Alo, Welfare. Emergency department care 2017-18: Australian hospital statistics. Canberra: AlHW; 2018.

8. Turner J, O'Cathain A, Knowles E, Nicholl J. Impact of the urgent care telephone service NHS 111 pilot sites: a controlled before and after study. BMJ open. 2013;3(11):e003451.

9. Toloo GS, FitzGerald GJ, Aitken PJ, Ting JY, McKenzie K, Rego J, et al. Ambulance use is associated with higher self-rated illness seriousness: user attitudes and perceptions. Academic emergency medicine: official journal of the Society for Academic Emergency Medicine. 2013;20(6):576-83.

10. Northington WE, Brice JH, Zou B. Use of an emergency department by nonurgent patients. Am J Emerg Med. 2005;23(2):131-7.

11. O'Cathain A, Connell J, Long J, Coster J. 'Clinically unnecessary' use of emergency and urgent care: A realist review of patients' decision making. Health expectations: an international journal of public participation in health care and health policy. 2020;23(1):19-40.

12. Redstone P, Vancura JL, Barry D, Kutner JS. Nonurgent use of the emergency department. The Journal of ambulatory care management. 2008;31(4):370-6.

13. Coster JE, Turner JK, Bradbury D, Cantrell A. Why Do People Choose Emergency and Urgent Care Services? A Rapid Review Utilizing a Systematic Literature Search and Narrative Synthesis. Academic emergency medicine: official journal of the Society for Academic Emergency Medicine. 2017;24(9):1137-49.

\section{Figures}


Pre-Study Period

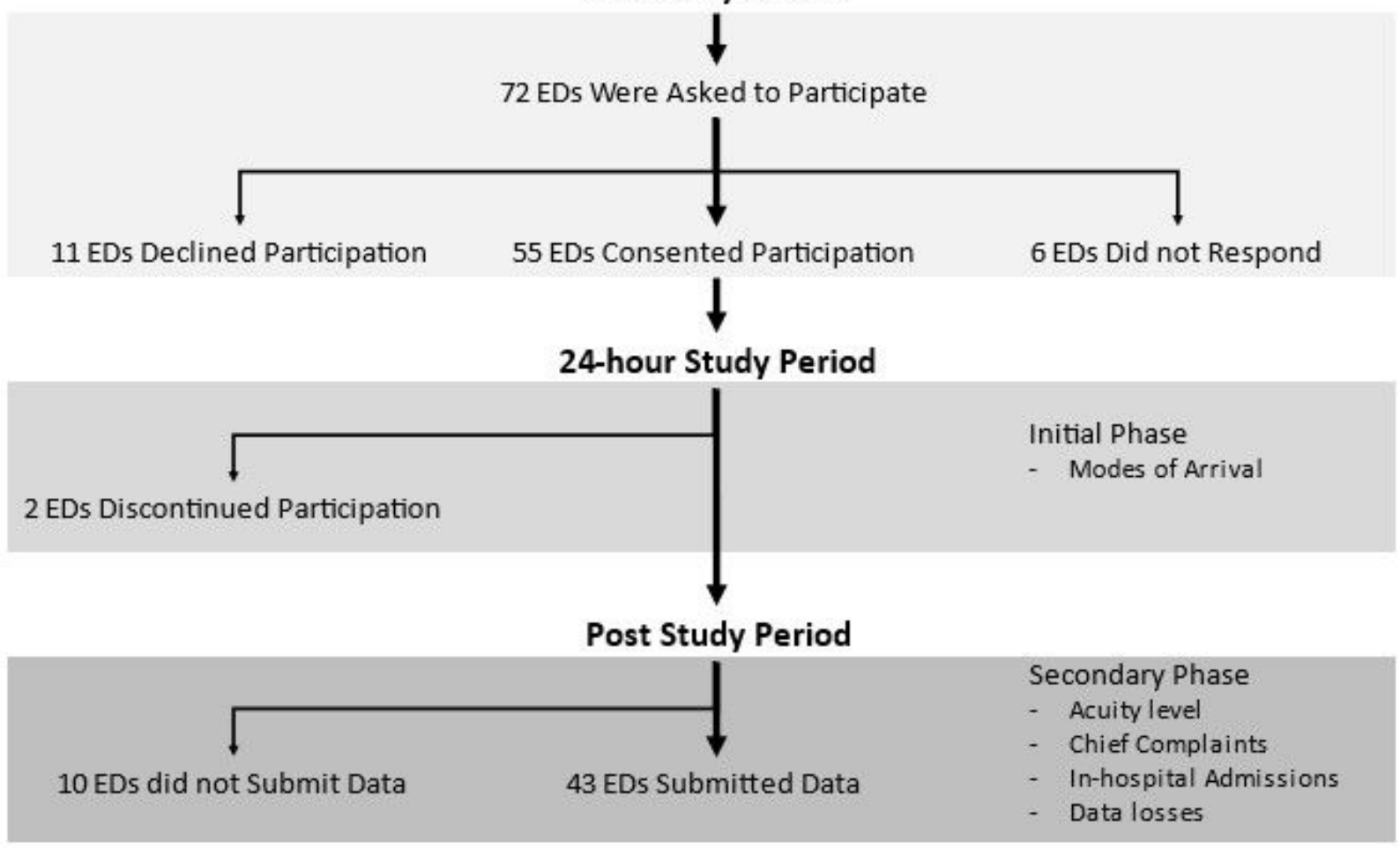

\section{Figure 1}

Schematic of the recruitment process, data acquisition processes and number of participating emergency departments (EDs) in the study.

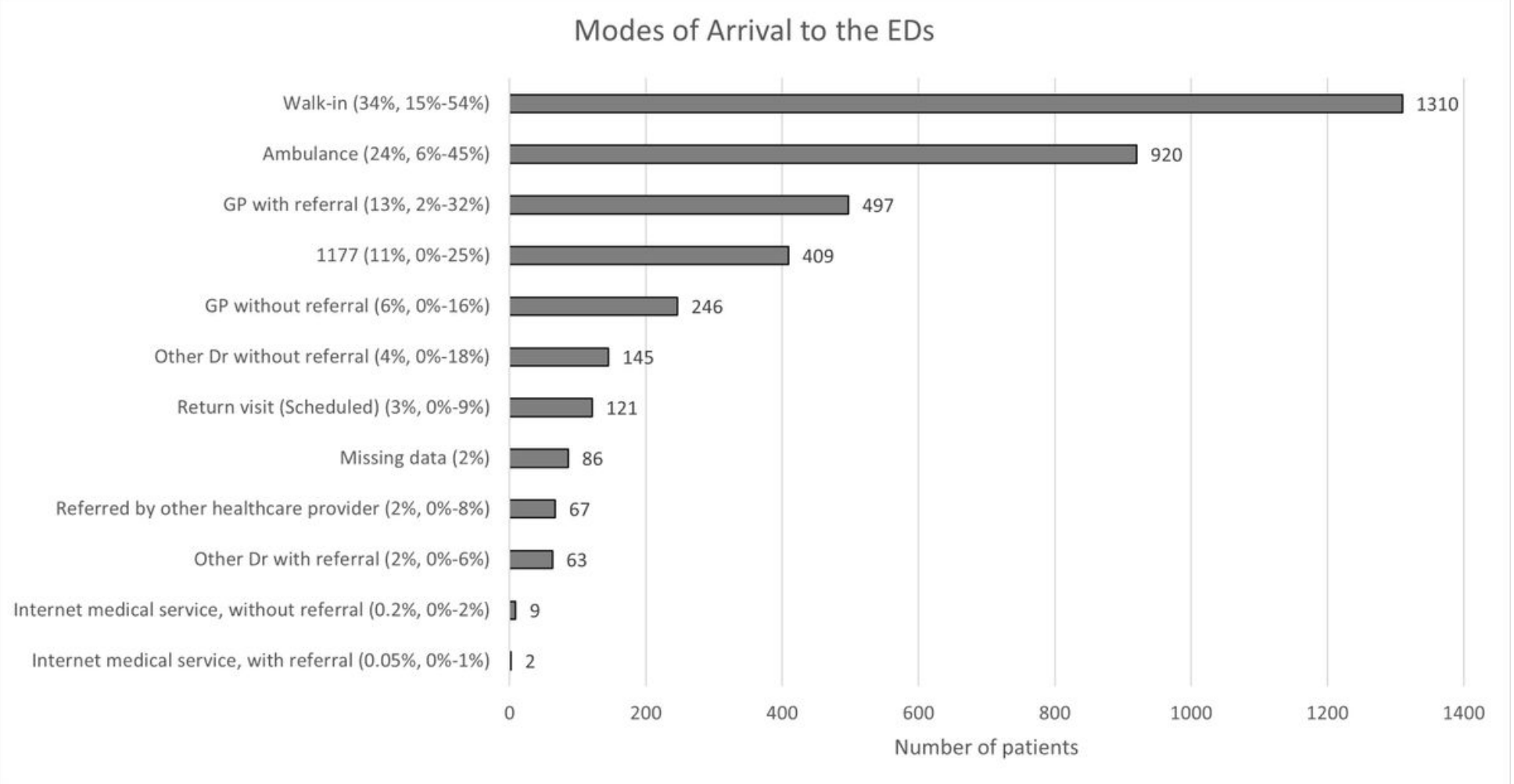

Figure 2 
The number and percentage of patients per mode of arrival among the 3875 patients at the 43 participating emergency departments (EDs) during the 24-hour study period. The percental range (\%) show the the lowest and highest reported percentage for each mode of arrival among the 43 participating EDs.

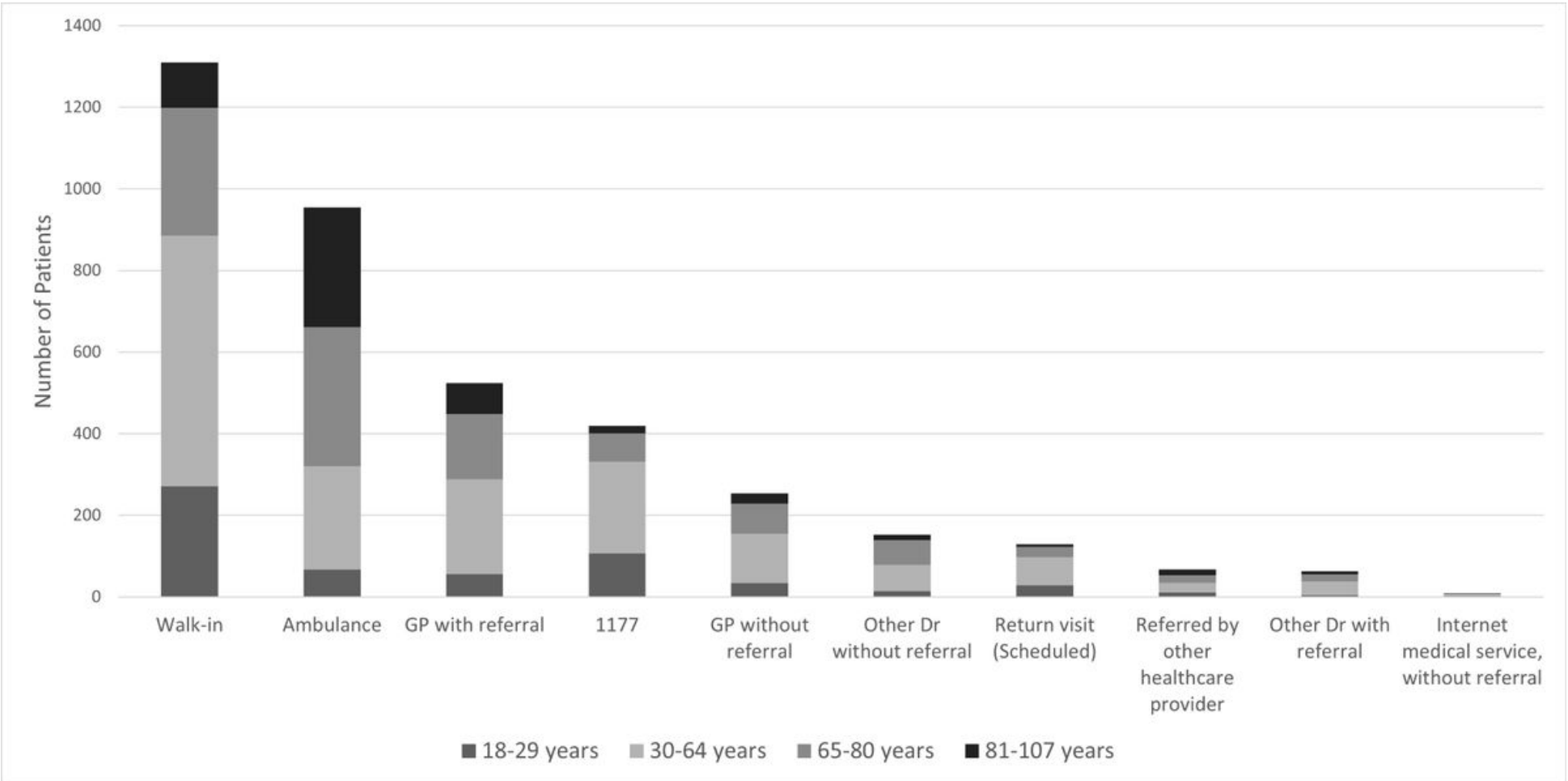

\section{Figure 3}

Number of patients per mode of arrival depending on age interval.

\section{Supplementary Files}

This is a list of supplementary files associated with this preprint. Click to download.

- Appendix1.docx

- Appendix2.docx 